\title{
LA INVENCIÓN DE LA MUJER MODERNA EN LA EDAD DE PLATA
}

\section{THE INVENTION OF THE MODERN WOMAN IN THE SPANISH SILVER AGE}

\section{Author / Autora:}

Ángela Ena Bordonada

Universidad Complutense de Madrid

Madrid, Spain

aaena@ucm.es

https://orcid.org/0000-0002-4378-1738

Submitted / Recibido: 08/06/2020

Accepted / Aceptado: 28/10/2020

To cite this article / Para citar este artículo: Ena Bordonada, Ángela. «La invención de la mujer moderna en la Edad de Plata». In Feminismo/s, 37 (January 2021). Monographic dossier: La mujer moderna de la Edad de Plata (1868-1936): disidencias, invenciones y utopias. Dolores Romero López (coord.): 25-52.

https://doi.org/10.14198/fem.2021.37.02

Licence / Licencia:

This work is licensed under a Creative Commons Attribution 4.0 International.

\section{(c) (i)}

(C) Ángela Ena Bordonada

\section{Ángela ENA BORDONADA}

\section{Resumen}

El objetivo de este ensayo es destacar, en una visión panorámica, la responsabilidad de unas mujeres de finales del siglo XIX y principios del XX -escritoras, periodistas, pedagogas, y, en general, mujeres con inquietudes sociales e intelectuales- en la modernización de la mujer española, ejerciendo un didactismo insistente desde sus ensayos, artículos periodísticos, conferencias, alocuciones radiofónicas y en sus ficciones literarias, consiguiendo la «invención» de la mujer moderna, antes incluso de que esa mujer se normalizase en la realidad española de la época.

Palabras clave: mujer moderna; primer tercio del siglo XX; misoginia; periodismo femenino; asociacionismo; trabajo femenino; literatura femenina.

\begin{abstract}
The aim of this essay is to highlight, in a wide vision, the responsibility of some women from the late 19th century and early 20th century -writers, journalists, pedagogues, and in general women with social and intelectual inquisitiveness- in the modernization of the Spanish woman, through a persistent didacticism in their essays, journalistic articles,
\end{abstract}


lectures, radio speeches and literary fiction writings, achieving the «invention» of the Modern Woman even before that woman was normalized in the Spanish reality of the moment.

Keywords: Modern Woman; Silver Age Spain; Misogyny; Women's journalism; Association; Women's work; Women's literature.

\section{INTRODUCCIÓN}

El presente estudio pretende mostrar, bajo una visión panorámica, cómo las mujeres españolas, en solo unas décadas, viven una serie de cambios que les permiten incorporarse a la modernidad del siglo veinte, siendo muchas de esas mujeres protagonistas e impulsoras de dicha modernidad. Reconozco el riesgo que representa tratar en un espacio limitado de un tema complejo y sobre el que ya hay una sólida bibliografía: desde los pioneros estudios de María de Campo Alange y de Antonina Rodrigo en su empeño por hacer visible la existencia de aquellas «mujeres silenciadas», a los posteriores nombres ya considerados clásicos en los corpus bibliográficos sobre la mujer y la escritora del primer tercio del siglo XX y, algunos, sobre su labor modernizadora, de los que, entre otros, destacan Mary Nash, Susan Kirkpatrick, Shirley Mangini, Iris Zavala, Geraldine Scanlon, Rosa Capel, Neus Samblancat, Pura Fernández, M.C.Simón Palmer, M. ${ }^{a}$ Francisca Vilches, Pilar Nieva, Nuria Capdevila, Pilar Celma, Mercedes Gómez Blesa, Helena Establier, Nerea Aresti, etc. A estos se van sumando las más jóvenes promociones de investigadores e investigadoras que traen innovadores enfoques sobre la mujer de aquella época. Por el carácter general de este ensayo y su limitada extensión, se prescinde de atender individualmente estas aportaciones, que constituyen la argamasa cimental de todo conocimiento actual sobre la mujer de las primeras décadas del siglo XX, por lo que están siempre presentes en nuestro hacer.

Tras muchos años de dedicación a la literatura femenina de ese periodo, mi intención actual es, pues, poner de relieve, una vez más, la responsabilidad de unas mujeres excepcionales que, desde su propia obra y observando lo que se estaba haciendo fuera de España, dirigen sus esfuerzos a lo que quiero llamar la «invención de la mujer moderna» en la España de principios 
del siglo XX. Ese empeño no quedó solo en el papel escrito o en la palabra de la oradora, sino que dio sus frutos en distintos ámbitos de la sociedad española, tanto privados como sociales y públicos a lo largo del primer tercio de la pasada centuria, ámbitos que intentaré recordar aquí.

Sabemos que no fue un proceso fácil. La mujer con afanes innovadores encontró obstáculos que, hoy, pueden resultar difíciles de comprender, de modo que aquel movimiento modernizador de la mujer solo puede valorarse en su justa medida, teniendo presente el ambiente hostil que acogió cualquier iniciativa femenina orientada a proporcionar un progresivo, aunque definitivo, «jaque al ángel del hogar» (Ena, «Jaque»). Basta un breve muestreo de las airadas actitudes que aquellas mujeres y sus obras artísticas -literarias, plásticas y musicales- recibieron de sus contemporáneos (Ena, Novelas 11-19; Sáez; Plaza Angulo). Recuérdese -no es nuevo-que, a principios del XX, todavía se mantiene el tradicional rechazo de la educación y la culturización de la mujer, exaltándose, por el contrario, la ignorancia como virtud femenina. Véanse dos ejemplos de 1911. En dos cuentos de la antología Literatura moderna (Barcelona, Librería de Feliu y Susanna), en la que publican también dos escritoras, Carmen de Burgos y Violeta (Consuelo Álvarez), aparecen los siguientes textos: «gentes felices, mozas sin contaminar aún, que viven muy a gusto sin leer libros de filosofía ni críticas bibliográficas», de Emiliano Ramírez Ángel $(7)^{1}$; «Ella misma, en su pudorosa ignorancia de mujer educada muy españolamente» [la cursiva es del original], de Luis G. Huertos (151). Como es sabido, las críticas se acentúan contra la «literata». Apenas se ha matizado el tratamiento despectivo que aparece en tantos textos decimonónicos ${ }^{2}$. Ya en el siglo XX, raramente los méritos literarios de las escritoras son reconocidos con objetividad. Pueden recibir críticas condescendientemente paternalistas, otras que rezuman un misoginismo implacable, y otras muchas que, al elogiarlas, les atribuyen valores masculinos ${ }^{3}$. Se

1. La primera edición de esta obra había aparecido en Los Cuentistas (julio de 1910).

2. El tan conocido texto de Eduardo Saco, «La literata» (1871), o la anterior visión de Juan Gutiérrez del Alba en Una mujer literata (1851), obra cómica teatral -de amplia difusión, por lo tanto-, destinada a señalar la cocina como lugar adecuado para la mujer (Gies).

3. Sorprende que este concepto de la literatura femenina de aquella época sea mantenido por el prestigioso hispanista Gonzalo Sobejano en su imprescindible Novela española

Feminismo/s 37, January 2021, 25-52 
podría construir un sustancioso repertorio de estas últimas, donde aparecerían firmas de ilustres escritores y periodistas, como los siguientes textos de Rubén Darío. El primero, en «La mujer española», de 1900, alaba a Pardo Bazán y a Concepción Arenal por sus «cerebros viriles», junto a un generalizado ataque contra las escritoras:

En este siglo, las literatas y poetisas han sido un ejército, a punto de que cierto autor ha publicado un tomo con el catálogo de ellas -iy no las nombra a todasi- Entre todo el inútil y espeso follaje, los grandes árboles se levantan: Coronado, la Pardo Bazán, Concepción Arenal. Estas dos últimas, particularmente, cerebros viriles, honran a su patria. $(326)^{4}$

El segundo texto, del mismo Darío, pertenece a una carta que escribe desde París, el 20 de agosto de 1911, a Carmen de Burgos. Le propone publicar en la revista Mundial que él dirige, la ensalza rechazando considerarla «literata»y, finalmente, afirma que, por sus méritos, debe usar masculinos «calcetines» en lugar de femeninas «medias»:

Ha sido para mí un gran placer el conocerla, por su talento y gentileza, y encontrar en usted la menor cantidad de «literata» posible. Nada de basbleu. Desde luego, como escritora, usted no usa medias sino calcetines... Quedo muy atento y cordialmente S.S.S. RUBÉN DARÍO. (Ghiraldo 473)

Haciendo frente a estos obstáculos, el proceso de modernización de la mujer española consiguió visibilidad en un periodo fecundo aunque breve (Mangini; Nieva; Gómez Blesa, Modernas), interrumpido trágicamente por

de nuestro tiempo -todavía en su 3. a edición, de 2005- al usar como única fuente, para este aspecto, La nueva literatura (vol. II, 228) de Rafael Cansinos-Assens, habitual detractor de nuestras escritoras. Dice Sobejano: «La literatura escrita por mujeres ha sido en España bastante escasa y raras veces auténticamente femenina. La mejor novelista del pasado, Emilia Pardo Bazán, escribía buscando y casi siempre alcanzando, mentalidad varonil. Todavía en 1919, haciendo un balance de la literatura española escrita por mujeres, afirmaba un crítico: «Las musas inspiradoras se han limitado, por lo general, a repetir las palabras de los hombres inspirados. Entre nosotros, la psicología femenina hay que buscarla en las obras de nuestros novelistas» (98).

4. En favor de Rubén Darío, está la denuncia que hace, en el mismo texto, de la situación del trabajo femenino en España: «en España, 6.700.000 mujeres carecen de ocupación, y 51.000 se dedican a la mendicidad. Fuera de las fábricas de tabacos, costuras y modas y el servicio doméstico, en que tan míseros sueldos se ganan, la mujer española no halla otro refugio» (327).

Feminismo/s 37, January 2021, 25-52 
la guerra del 36, cuyas consecuencias fueron más nefastas para las mujeres, al quedar anulados por decreto y sepultados en un olvido dirigido, los logros obtenidos por aquel importante movimiento femenino de las primeras décadas del XX, además de obligar al exilio a muchas de aquellas mujeres, tal vez las mejores, con lo cual ese olvido y sus efectos fueron irremediables, pues, como recuerda Nieva, supuso una gran pérdida de ese «mundo intelectual y político de singular riqueza» que se había construido en los años veinte y treinta. La misma Nieva recuerda los nombres de destacadas escritoras e intelectuales que debieron exiliarse y, aunque muchas pudieron recuperar sus actividades en los lugares de acogida, sus obras tardarían décadas en llegar a España, e, incluso, algunas permanecieron en un semiolvido hasta casi la actualidad. Así, María Lejárraga, Matilde de la Torre, Elena Fortún, Isabel Oyarzábal, Zenobia Camprubí, Margarita Nelken, Magda Donato, Rosa Chacel, Concha Méndez, M. ${ }^{a}$ Teresa León, María Zambrano, Luisa Carnés, Ernestina de Champourcín, Federica Montseny, Carlota O'Neill, etc. (Nieva 21).

Sin embargo, la simiente que aquellas mujeres sembraron había germinado y hubo Andreas, chicas raras, o menos raras, pero siempre mujeres igualmente excepcionales que, en la posguerra, mantuvieron viva la llama de aquellos cambios. Muchas se habían educado en los planes pedagógicos de la República, formándose en las lecturas y el espíritu reivindicativo de la preguerra, que resume el mensaje que, en 1927, en la revista Ondas, en un número monográfico sobre los beneficios de la radiofonía para la mujer -en el que solo colaboran mujeres- lanza Victoria Kent, que supo ver el destino de la mujer en el siglo XX: «El siglo XX va a abolir las diferencias sociales entre el hombre y la mujer [...] Con todos sus defectos, el siglo XX es el siglo de la dignificación de la mujer» (Ena, «Modernidad» 137). Los cimientos de esa dignificación se habían puesto en aquellas primeras décadas de la pasada centuria y aun antes.

La fotografía nos permite observar el alcance y rapidez con que la mujer consigue su incorporación a la más llamativa modernidad. Aunque puedan resultar anecdóticas, resultan reveladoras ciertas imágenes que ilustran la prensa cotidiana de la época. Destaco tres noticias de 1931.

El 17 de junio de 1931, el semanario Mundo Gráfico publicaba una fotografía de Victoria Kent, que, dos meses antes, había sido nombrada Directora 
General de Prisiones. El pie de la fotografía dice: «La directora de Prisiones, señorita Victoria Kent, escuchando a un recluso que le entregó un ramo de flores». Era la primera mujer española que ocupaba un alto cargo político y se la ve rodeada de hombres, con un ramo de flores en las manos, que le había sido entregado, siguiendo las normas de la cortesía hacia una mujer.

En el mismo número de Mundo Gráfico, aparece otra fotografía, de contenido distinto, pero igualmente significativo: un grupo de jóvenes madrileñas, en traje de baño, dispuestas a bañarse en una piscina pública. Dice el pie de la fotografía: «Un ramillete de lindas nadadoras de las que frecuentan la piscina de Chamartín, subidas en la palanca, desde la que se lanzan al agua». Todas muestran alegría, desenfado y complexión atlética. Lejos -aunque, en tiempo real, menos de dos décadas-quedan el pudor y decoro impuestos a las jóvenes y los trajes que ocultaban la casi totalidad del cuerpo femenino.

Y en la misma revista, en el número de la semana anterior, 10 de junio de 1931, otra fotografía muestra a una joven sonriente montada en un avión, luciendo corbata y gorro de piloto: «En el Club deportivo del Aire. La bellísima señorita de Linares Rivas que, con el piloto señor Ansaldo, hizo el domingo último, en el aeródromo civil, brillantes demostraciones de acrobacia» $»^{5}$.

A no ser por el atuendo femenino, que nos habla de otra época, y la escasa calidad de las imágenes, la publicación de estas instantáneas en la prensa actual no resultaría extraña referida a la mujer de hoy, del siglo XXI. Sin embargo, al ser publicadas en 1931, son muestra de los logros que, para esa fecha, había conseguido la mujer española en una línea de reivindicaciones, desde el derecho a una educación útil para la mujer, que le facilitase un trabajo digno, pudiendo independizarse de la obligada tutela de un hombre de su entorno familiar, a su conciencia de ciudadana, reclamando el voto y otros derechos legales.

Las imágenes comentadas, de 1931, ilustran la culminación de estos cambios, que alcanzan mayor auge en los años treinta, particularmente durante

5. Es Nena Linares Rivas, hija del dramaturgo Manuel Linares Rivas. El piloto, cualquiera de los tres hermanos Ansaldo Verajano, los tres, pilotos: Juan Antonio -el más célebre, pionero de la aviación española-, Francisco y José María. Los tres estaban casados con mujeres que también pilotaban aviones. 
la República (Gómez Blesa, Las intelectuales; Nieva). Pero sería injusto olvidar que aquel proceso de modernización de la mujer se inicia a principios del siglo XX y, antes, desde las últimas décadas del XIX, cuando los medios eran más adversos (Sánchez García; Gómez Blesa, Modernas). Particularmente, desde comienzos del XX, buen número de mujeres -escritoras, periodistas, pedagogas, $y$, en general, mujeres con inquietudes sociales e intelectuales-, por encima de divergencias ideológicas, coinciden en presentar unos rasgos que las distinguen de sus antecesoras decimonónicas. Poseen una instrucción más completa, muchas han recibido una enseñanza secundaria, algunas, en menor número, asisten a la Universidad, y, lo más importante, son ya verdaderas profesionales que, en la mayoría de los casos, viven de su trabajo.

Como dato que hay que tener en cuenta, estas mujeres se enfrentan a los rigurosos esquemas sociales, religiosos y familiares que regían la conducta de la mujer. Son muchas las que, casadas, rompen su matrimonio o viven distanciadas del marido, buscando, o no, otra relación: Carmen de Burgos, Sofía Casanova, Ángeles Vicente, Concha Espina, M. ${ }^{a}$ Teresa León, Luisa Carnés, entre otras. Concha Espina, aunque separada de su marido desde 1909, será la primera de nuestras escritoras que se beneficia de la ley del divorcio en 1932, ley que será derogada el 23 de septiembre de 1939; Margarita Nelken, ya madre soltera de una hija y de un hijo, se casará con quien fue su marido -aunque terminará separándose- cuando él puede divorciarse de su primera mujer; Magda Donato será la compañera de Salvador Bartolozzi, casado y con hijos; caso especial y conocido es el de María Lejárraga, etc.

Por otra parte, hoy estamos conociendo, con documentación certera (Simonis, Capdevila), cómo otras de aquellas mujeres vivieron una afectividad homosexual que la mayoría mantuvo oculta bajo una apariencia de respetable matrimonio o de respetable soltería. Recordemos a Elena Fortún, Matilde Ras, Carmen Conde, Victoria Kent, Ana M. ${ }^{a}$ Martínez Sagi, el fugaz episodio de Elisabeth Mulder con la anterior, la presumible homosexualidad de Víctor Català (Ena, «Un relato»), la conocida bisexualidad de Maruja Mallo; la escenógrafa y pintora, Victorina Durán ${ }^{6}$, nunca ocultó su

6. Remito al ensayo de Moreno Lago en este número de Feminismo/s, «El círculo sáfico de Madrid: intelectuales en torno a una sexualidad disidente», y a sus estudios sobre Victorina Durán. 
lesbianismo, como tampoco lo ocultó la excéntrica y popular aristócrata Gloria Laguna (Usó); etc.

\section{DIDACTISMO DE LA MUJER PARA LA MUJER}

En general, aquellas fueron mujeres valientes, inconformistas que -ya se ha dicho- habían dictado el 'jaque mate' al decimonónico 'ángel del hogar', a la vez que iban alcanzando unos espacios de la sociedad que antes les estaban vedados o tradicionalmente se asignaban al hombre.

Profesionales en distintos campos, estas mujeres ejercen un didactismo dirigido a la modernización de la mujer española a través de sus ensayos, sus artículos periodísticos, conferencias, también desde los micrófonos de la primitiva radiofonía, y, de modo muy eficaz, en sus ficciones literarias con la innovadora construcción de sus personajes femeninos. Son, como las denomina tan acertadamente Gómez Blesa (Modernas) mujeres-faro, pues sirvieron de guía a otras mujeres que vinieron detrás.

Se podría decir -ya lo adelantó hace dos décadas Amparo Hurtado (139)que este insistente y continuado aleccionamiento sobre la nueva mujer llega a «inventar» a la mujer moderna, es decir, a trazar un modelo a seguir, antes incluso de que esos cambios renovadores alcanzasen a la mujer común en la realidad española. Y ese infatigable didactismo aleccionador, sobre todo cuando se difunde por la prensa y en las ficciones novelescas - por tener un público más amplio-, consigue algo más importante: que la mujer, sus problemas y sus necesidades se hicieran visibles para la sociedad en general y para las propias mujeres que eran sus principales lectoras, a quienes incitan a seguir ese camino innovador.

Este didactismo de la mujer dirigido a la mujer se inicia en las últimas décadas del siglo XIX. Además de las fundamentales contribuciones de Concepción Arenal, de Emilia Pardo Bazán ${ }^{7}$ y de otras pioneras (Gómez Blesa, Modernas; Sánchez García), quiero fijarme, como perfecto exponente, en otra brillante mujer de entresiglos, Concepción Gimeno de Flaquer (1850-1919) (Pintos; Bianchi): narradora, ensayista, defensora de los derechos de la mujer -ya en 1877 publica La mujer española. Estudios acerca de su educación y sus

7. Thion Soriano-Mollá trata, en este número de Feminismo/s, sobre «La forja de la mujer intelectual moderna de la Edad de Plata: Emilia Pardo Bazán». 
facultades intelectuales-, fundadora de revistas femeninas como La Ilustración de la Mujer (1873) o El Álbum de la Mujer, publicada en México, que luego, en España, convierte en El Álbum Ibero-americano (1890). Gimeno de Flaquer fue quien habló de feminismo por primera vez en una tribuna tan prestigiosa como la del Ateneo de Madrid, antes de que esta Institución admitiese a la mujer como socio de número. El 6 de mayo de 1895, había hablado sobre Ventajas de instruir a la mujer y sus aptitudes para instruirse, y, el 26 de mayo de 1903, pronuncia una importante conferencia, El problema feminista, con gran éxito de público, donde expone su concepto de «feminismo moderado», «sin soluciones violentas», pero planteando las bases de la modernización de la mujer española. Ahí están sus numerosas denuncias: desde la injusta situación de la mujer ante la ley -matrimonio, patria potestad de los hijos, etc.- a las limitaciones laborales que la mujer sufre, para la que pide mejor remuneración y mayores salidas profesionales: banca, bibliotecas, museos, administración, trabajos artísticos, literarios, científicos, etc. (Pintos 20-22; Ezama, Las nuevas musas 168). Gimeno de Flaquer diseña la «Eva moderna» -como titularía una novela en 1909: Una Eva moderna- en su narrativa, de la que aquí no trato, en sus ensayos -La mujer juzgada ante el hombre (1884), Evangelios de la mujer (1900), La mujer intelectual (1901), etc.-, y en sus artículos periodísticos, de los que cito algunos publicados en El Álbum Ibero-americano: «La mujer de nuestros días» (1885), «La mujer estudiosa» (1886), «La misión de la mujer» (1893), «Feminología» (1904), «Feminismo» (1904), «El sufragio femenino» (1906), etc. Y, como Carmen de Burgos hará unos años después, atiende también otros temas de «la mujer en sociedad»: En el salón y en el tocador. Vida social. Cortesía. Arte de ser agradable (1899).

Resultan hoy sorprendentes las directrices modernizadoras contenidas en estos y en tantos otros ensayos de diversas autoras que, sobre todo, a lo largo del primer tercio del XX, tienden a despertar una conciencia emancipadora en la mujer de la época, además de sacar a la luz los perfiles que han de definir a la «mujer moderna». Obsérvese que el término 'mujer' preside los títulos, complementados frecuentemente por el adjetivo 'moderna' con lo que el mensaje resulta inequívoco ${ }^{8}$. Recordemos, como meros ejemplos

8. Quiero destacar aquí el acierto de Shirley Mangini al recoger este mensaje de «mujer» y «moderna» en su revelador ensayo Las modernas de Madrid. Las grandes intelectuales 
de este didactismo ejercido por mujeres de diversas ideologías, algunos títulos de Carmen de Burgos: La mujer en España (1906), La mujer moderna y sus derechos (1927); de Carmen Karr: Cultura femenina (1910); de Margarita Nelken": La condición social de la mujer en España (1919), En torno a nosotras (1927), La mujer ante las Cortes Constituyentes (1931); de Carmen Díaz de Mendoza: Educación feminista (1922), Política feminista (1923); de María Cambrils: Feminismo socialista (1925); de María Lejárraga: La mujer española ante la República, donde recoge las cinco conferencias pronunciadas en el Ateneo, en mayo de 1931, y, antes, firmados por su marido, Gregorio Martínez Sierra, aparecieron otros ensayos como Cartas a las mujeres de España (1916), Feminismo, españolidad, españolismo (1917), La mujer moderna (1920); de Clara Campoamor, El derecho de la mujer (1931); de Federica Montseny, La mujer, problema del hombre (1932); etc.

Por otra parte, están las revistas orientadas a un público específicamente femenino. Incluso aquellas que tratan de temas «propios para la mujer», aparentemente herederas de algunas publicadas en la segunda mitad del siglo XIX, reflejan nuevas ideas sobre la casa, la higiene, la dieta, la moda o la educación de los hijos. Es el caso de la popular El Hogar y la Moda (1909-1987), dirigida desde 1921 por la periodista y escritora María Luz Morales (Servén, labor), donde los temas tradicionalmente considerados como femeninos se combinan con aquellos que deben interesar a la mujer moderna (deportes, viajes, cine, etc.). Además, desde 1921, se publica su suplemento literario, Lecturas, donde el amplio público femenino al que va destinado encuentra firmas destacadas de la literatura de la época, entre las que no faltan autores tan poco populistas como Unamuno, Valle-Inclán, Azorín, y, sobre todo, una amplia galería de escritoras: Concha Espina, Carmen de Burgos, Sofía Casanova, las hermanas Nelken, Víctor Català, las más jóvenes Elisabeth Mulder, Ana M. ${ }^{a}$ Martínez Sagi, Carmen Conde, etc. (Labajo González).

Igualmente, aparecen nuevas revistas que, además, recogen contenidos sociales, políticos y feministas, apoyadas por determinados grupos o

españolas de la vanguardia, que contribuyó -ya hace dos décadas- a acuñar y poner en circulación el concepto de «mujer moderna», tan desarrollado en la bibliografía posterior sobre la mujer.

9. Nelken escribe también Las escritoras españolas (1930), ensayo pionero en la recuperación de la literatura femenina desde «los albores del cristianismo» hasta Pardo Bazán. 
asociaciones femeninas, como La Voz de la Mujer (1917-1931), fundada y dirigida por Celsia Regis (Rota, «La Voz»), o Mundo femenino (1921-1936), ambas próximas a la Asociación Nacional de Mujeres Españolas.

El lugar que va ocupando en la sociedad la mujer -como sujeto y, también, como objeto- motiva que la prensa general -ya desde finales del XIX, cuando inicia su modernización- publique secciones fijas dirigidas a la mujer, donde no solo se habla de moda, de cocina o de la infancia. Y ahí entran nuestras escritoras convertidas en activas periodistas, autoras de artículos y de columnas fijas, donde desgranan los asuntos más diversos en torno a la mujer o sobre asuntos generales, pero enfocados desde una nueva mirada de mujer. Estas secciones no faltan en la prensa diaria ni en las revistas de información general que alcanzan grandes tiradas: La Ilustración Española y Americana, Blanco y Negro, Por Esos Mundos, La Esfera, Estampa, etc. Últimamente han aparecido varias publicaciones generales sobre las escritoras en la prensa de la época: Bernárdez; Bernard y Rota; Palomo y Núñez; Ramírez; Servén y Rota.

Además de ejercer su labor didáctica en pro de la mujer, estas escritoras se convierten en destacadas profesionales del periodismo que, como para sus colegas masculinos, es, también para ellas, una importante fuente de ingresos. Conocida es la amplia actividad periodística de Carmen de Burgos (Núñez) -firmó más de 2.000 colaboraciones-, primera española redactora en nómina, autora de columnas fijas como «Lecturas para la mujer» en Diario Universal, en 1903, donde, en 1904, levanta polémica con el tema del divorcio; «Femeninas», en Heraldo de Madrid desde 1906, donde ese mismo año popularizó su campaña en favor del voto femenino, y, en 1909, sus crónicas sobre la guerra de Marruecos, siendo la primera mujer española que escribe sobre una guerra in situ. Colaboró, además, en La Correspondencia de España, El Pueblo de Valencia, Nuevo Mundo, Por Esos Mundos, La Esfera y otras publicaciones nacionales y extranjeras; María Lejárraga firma la columna «La mujer moderna», en Blanco y Negro, entre 1915 y 1916; Margarita Nelken, «La vida y las mujeres» en El Día, entre 1916 y 1918, y «Temas femeninos. La vida y nosotras» en Blanco y Negro, en 1930; Violeta [Consuelo Álvarez Pool] publica su columna «Carnet Femenino» en El País, entre 1904 y 1919 (Crespo); Magda Donato, su «Femeninas» en El Imparcial desde 1917, «Vida femenina» en La Tribuna desde 1919, «Crónicas» en el Heraldo de Madrid, en 1926, y la

Feminismo/s 37, January 2021, 25-52 
serie de «reportajes vividos», con frecuente protagonismo femenino, en Ahora (1932-1936) (Bernard, «Los reportajes»). O las colaboraciones en El Sol de Isabel Oyarzábal, «Diario de una mujer», en 1917, y «Crónica femenina», en 1918 (Quiles), además de fundar y redactar las revistas La Dama y La Vida Ilustrada (Bados); María Luz Morales, además de dirigir El Hogar y la Moda, escribe, desde 1926, la sección «La Mujer, el Niño y el Hogar»- incluyendo temas de trabajo, cultura y arte- en La Vanguardia, diario que dirigiría en 1936, siendo la primera mujer directora de un gran diario nacional (Servén, «Literatura»). A finales de los años veinte, inicia su larga trayectoria en el periodismo Josefina Carabias. En 1928, entra en Estampa, luego en Mundo Gráfico, Crónica y Ahora, siendo redactora fija en La Voz. En la posguerra, tras sufrir problemas con el régimen franquista, llegó a ser influyente periodista y corresponsal en los años cincuenta y sesenta (Ezama, «Las colaboraciones»).

\section{IMAGEN Y MODA}

Sin poder detenernos en ellas, hay que recordar que los aires renovadores llegan a las columnas sobre la moda, en publicaciones de información general. Cuando van firmadas por mujeres progresistas, como Carmen de Burgos, Teresa de Escoriaza o Magda Donato, introducen una nueva visión, con frecuencia irónica, que consigue desmitificar el acartonado imperio de la moda. Así, Magda Donato, en «Páginas de la mujer» (Estampa, desde 1928), construye cuadros sobre la moda y sus usos sociales, con frecuencia desde el humor y la ironía (Bernard, «Moda»).

Es precisamente en la moda y el vestuario femenino donde hallamos un fiel testigo del rápido proceso de modernización de la mujer que tiene lugar en unas décadas. La imagen externa de la mujer habla elocuentemente de aquellos cambios. Conviene recordar que en este tiempo la mujer, también en España, protagoniza una serie de hechos por primera vez en la historia, hechos que pueden parecer triviales, pero no lo son: marcan el signo de la época, proporcionando a la mujer una libertad corporal y material, de acuerdo con las nuevas actividades que puede desarrollar, que exigían un cambio en su aspecto e indumentaria. María Lejárraga recuerda los problemas que tuvo al llegar por tren, ella sola, a la estación de Bruselas, en una 
tarde de viento y lluvia de 1905, para sujetar el paraguas con una mano, recogerse la falda larga con la otra... ¿y el equipaje menudo?

En aquel tiempo, las mujeres llevábamos vestidos larguísimos, y la mano derecha iba siempre ocupada fatigosamente en recoger los abundantes pliegues de la falda para que no arrastrasen por el suelo. Con la mano izquierda sostenía el paraguas, luchando contra el viento [...] (Martínez Sierra 270)

Efectivamente, las mujeres van eliminando prendas que deformaban su cuerpo y limitaban sus movimientos. Habían desterrado el polisón y pronto, el asfixiante corsé (Pasadolos). La falda se va acortando. Hacia 1910, y, sobre todo, desde la gran guerra de 1914, por primera vez en la historia, la falda de la mujer no pasa de sus rodillas, descubriendo sus piernas, con el consiguiente trastorno del código erótico establecido durante siglos, vigente aún en la época. También, por primera vez en la historia, la mujer se corta el cabello, siguiendo la moda de París, a lo garçon, lo que da pie a reacciones irónicas y misóginas. La fotografía nos muestra la rápida evolución de la imagen de la mujer común. No me refiero aquí a la mujer irreal, de aspecto sofisticado y cosmopolita, creada por la pluma de los dibujantes que ilustran las revistas y publicaciones de la época. La mujer real, tanto en las grandes urbes como en pequeños pueblos, no solo va acortando su falda, sino que, en la década de 1920, empieza a maquillarse suavemente los labios y los ojos y aplica a su cabello corto el rizado «permanent», imitando a las grandes estrellas del cinematógrafo (Ena, «El retrato»).

\section{EDUCACIÓN. FORMACIÓN DE LA MUJER INTELECTUAL}

Este cambio de imagen corre parejo a la progresiva incorporación de la mujer a la sociedad, no ya solo como pasiva espectadora-receptora, sino a través de su activa presencia en nuevos espacios. No es casual que un centro como el Ateneo de Madrid, al que no había accedido una mujer hasta $1882^{10}$ -entonces lo hizo un grupo de institutrices para asistir a una conferencia de historia-, inaugure la nueva centuria del XX concediendo, en 1905, el primer carnet de socia de número a doña Emilia Pardo Bazán, a la que, en

10. Luego, en 1884, Rosario de Acuña ofrece un recital de su poesía, y a partir de 1886 , Pardo Bazán deja constancia de su presencia y actividades. 
el mismo año, seguirían las también escritoras Blanca de los Ríos, Carmen de Burgos y la pintora Rafaela Sánchez Aroca. El número de socias iría en aumento, de modo que la presencia femenina se fue normalizando, aunque siempre en minoría, en las tribunas, tertulias y salones de la Institución (Ezama, Las nuevas musas)

Como es sabido, a lo largo de la segunda mitad del siglo XIX, la inquietud por la educación surge desde distintos sectores de la sociedad, en medios estatales, eclesiales y libertarios, destacando los varios congresos pedagógicos que intentan regularizar la enseñanza en España. De gran repercusión fue el Congreso Hispano-Portugués-Americano (Madrid, 1892), al que presentaron importantes ponencias Concepción Arenal y Pardo Bazán sobre la educación de la mujer (Ballarín; Sánchez García). Por su decisiva influencia en la rica floración intelectual y artística que define el primer tercio del siglo $\mathrm{XX}$, sobresale la corriente burguesa, laica, liberal progresista, que cristalizaría en la Institución Libre de Enseñanza, creada en 1876 por Francisco Giner de los Ríos y un grupo de profesores universitarios. La Institución supuso la renovación de los métodos pedagógicos, contribuyendo a la creación del intelectual de tipo europeo. De aquellas políticas educativas del siglo XIX, la mujer sería beneficiaria en las primeras décadas del siglo XX. Hay dos datos significativos: el descenso del analfabetismo en España -también entre las mujeres, particularmente, en las zonas urbanas - y, por otro lado, el progresivo aumento de la presencia de la mujer en los estudios universitarios (Capel, El trabajo). Si bien, como registra Flecha, varias españolas se licenciaron en Medicina, Farmacia y Filosofía y Letras, en las décadas de 1880 y de 1890, el avance llegó a partir de 1910, cuando el Ministro de Instrucción Pública, Julio Burell, permitió el acceso libre de la mujer a la Universidad, es decir, sin tener que solicitar autorización para ello, lo que supuso un ascenso de matriculaciones femeninas, aunque el mayor número se alcanza en la década de los veinte y durante la República. Esta mayor presencia femenina en la Universidad motivó que, cinco años después de la fundación de la mítica Residencia de Estudiantes, se crease, en 1915, la Residencia de Señoritas, dirigida por María de Maeztu (Zulueta y Moreno; Cueva y Márquez Padorno). Los organismos nacidos al amparo de la Institución Libre 
de Enseñanza contribuyeron a la formación de la mujer intelectual ${ }^{11}$. La Junta para Ampliación de Estudios, creada en 1907, puso en marcha centros de reconocimiento internacional en los que participan numerosas mujeres, con un programa de becas para estudiar o investigar en el extranjero, como el Centro de Estudios Históricos y el Instituto Nacional de Ciencias FísicoNaturales, o la Escuela de Estudios Superiores de Magisterio, fundada en 1909, para observar los planes educativos de otros países, fomentando el intercambio de estudiantes e investigadoras españolas con otras extranjeras (López-Ríos; Piñón; Rebok). En 1918, se funda el Instituto-Escuela, que practicó los sistemas pedagógicos europeos más avanzados, donde enseñaron intelectuales institucionalistas como María Goyri, María de Maeztu, Gloria Giner, Lucía Posada (hija de Adolfo Posada), etc., y donde se educaron las clases progresistas (Alcalá, Corrales y López 171 y ss.).

Paralelamente, se desarrollan otros proyectos educativos: el Instituto Internacional, estrechamente relacionado con la Residencia de Señoritas (Zulueta, Misioneras); el Centro Iberoamericano de Cultura Popular Femenina y Escuela de Madres de Familia (1906-1926), vinculado a la Asociación para la Enseñanza de la Mujer, fundada por Fernando de Castro (Ezama, «La educación»); la Escuela del Hogar y Profesional de la Mujer (1912-1926), impulsada por el ministro Burell, siguiendo modelos europeos. Y surgen otros proyectos de formación de la mujer, como la escuela de tipógrafas, fundada en 1919 por Celsia Regis, quien también proyectó, en 1927, una Escuela de periodistas, femenina, que quedó en tal proyecto (Rota, «La Voz»). Sin olvidar las escuelas -de origen decimonónico- que seguían atendiendo la formación de enfermeras, matronas, taquígrafo-mecanógrafas, archiveras y bibliotecarias, empleadas de correos y telégrafos, etc.

El abanico de posibilidades educativas y profesionales para la mujer se abre. Aunque la realidad se imponía, de modo que buen número de mujeres licenciadas y otras profesionales, sobre todo de las clases medias, abandonaban su actividad profesional ante el matrimonio y la maternidad. Pero algo estaba cambiando.

11. Remito a de la Cueva, en este número de Feminismo/s, «Una 'habitación propia' para las españolas». 


\section{VIAJES. CÍRCULOS. ASOCIACIONISMO}

Aquellas mujeres salen, viajan, se benefician de la facilidad que les ofrecen los nuevos medios de transporte - principalmente, el tren - y narran las novedades vividas en crónicas periodísticas, recogidas con frecuencia en libros de viajes. Pardo Bazán, Emilia Serrano, conocida como la baronesa Wilson, Carmen de Burgos, Sofía Casanova, Violeta, Concha Espina, Matilde de la Torre, Aurora Bertrana, Federica Montseny, etc., muestran en sus crónicas y en sus libros intereses diferentes, desde una mirada de mujer, a los de autoría masculina y, sobre todo, cuando recogen sus viajes al extranjero, se convierten en importantes vías de modernidad para España, descubriendo nuevamente la función educadora que la escritora ejerce sobre su público, fundamentalmente femenino (Ena, «La memoria»).

Y sienten necesidad de reunirse, de intercambiar ideas y amistades. Además de las tertulias literarias que en sus casas acogen Carmen de Burgos y Concha Espina, por citar las más célebres, fomentan los círculos y foros femeninos, tomando como modelo lo que se estaba haciendo en Europa y América. En 1926, un grupo de mujeres «cultas y modernas» funda el Lyceum Club (Aguilera, «Las fundadoras»), centro aconfesional y apolítico, con fines culturales, presidido por María de Maeztu, como vicepresidentas, Victoria Kent e Isabel Oyarzábal, y como secretaria, Zenobia de Camprubí. El Lyceum fue lugar de encuentro, de libertad y cultura, con secciones de Literatura, Música, Artes Plásticas e Industriales, Internacional, Hispanoamérica, y, sobre todo, generó un espíritu colectivo en defensa de los intereses de la mujer. Entre las socias, Carmen Baroja, Clara Campoamor, Ernestina de Champourcín, Victorina Durán, Matilde Huici, Elena Fortún, M. ${ }^{a}$ Teresa León, Concha Méndez y un largo etcétera.

El fenómeno del Asociacionismo femenino tiñe la época en un amplio arco ideológico. Desde la burguesía conservadora y católica a diferentes sectores progresistas, las mujeres, con inquietudes sociales, se agrupan en asociaciones nacionales e internacionales, frecuentemente vinculadas a revistas que testimonian los primeros pasos de un feminismo español que nunca fue radical (Scanlon; sin aceptar esa sostenida moderación, González Sanz). Así, la conservadora Lliga Patriótica de Dames, de la burguesía catalana, vinculada a dos revistas, Or i Grana (1906-1907), subtitulada Setmanari autonomista per 
a dones catalanes, que une catalanismo y feminismo, y Feminal (1907-1917), dirigida por Carme Karr, con importantes firmas femeninas de la literatura en catalán y castellano en ambas revistas (Simón Palmer, «Escritoras»). Por otra parte, la Iglesia (Arce), tras la encíclica Rerum Novarum (1891), aprovecha la labor de numerosas activistas católicas (María de Echarri, María Doménech, etc.) que fundan asociaciones destinadas a la protección de las mujeres obreras como la Federación Sindical de Obreras (1912), para contrarrestar la influencia de las Agrupaciones Femeninas Socialistas. En 1919, nace la poderosa Acción Católica de la Mujer, ante el reto que significa la aparición, un año antes, en 1918, de la Asociación Nacional de la Mujer Española (ANME) que, desde diversas posturas progresistas, aunque no radicales, y postulando un feminismo moderado, fue la más importante de la época ${ }^{12}$. La limitada extensión de este estudio impide tratar de otras asociaciones Federación Internacional Feminista (1919), Unión del Feminismo Español (1924) - y otras «redes» internacionales, tanto a nivel europeo, como las que estrechaban lazos entre escritoras españolas e hispanoamericanas y entre españolas y portuguesas (Aguilera y Lizárraga, De Madrid; Fernández, No hay nación; Ezama, «La Unión»).

\section{NUEVAS PROFESIONES PARA LA MUJER}

Con la incorporación, lenta pero imparable, de la mujer al trabajo se alcanzaba otro logro, tal vez el más importante para su emancipación. Si bien la imagen de la mujer en el trabajo ha sido poco visible, a excepción de las ocupaciones de sirvienta, «obrera de la aguja» o las relacionadas con la docencia y la enfermería, consideradas como apropiadas para el género femenino, sin embargo, hoy contamos con documentación que permite ir conociendo a mujeres pioneras en campos diversos, cumpliéndose lo que, en 1903, pedía Concepción Gimeno de Flaquer, en cuanto a mayores salidas profesionales para la mujer. La mujer está presente en la abogacía: las primeras colegiadas fueron María Ascensión Chirivella, en Valencia, 1922, y Victoria Kent, en Madrid, 1925, a las que siguieron otras diez hasta 1936 (Yanes). En ciencias: Carmen Gómez Escolar, Dorotea Barnés González, Ángela García de

12. Remito al estudio de Aguilera Sastre, en este número de Feminismo/s, «Para una historia de las asociaciones feministas en España». 
la Puerta, etc. (Magallón). Ejercieron la medicina algunas pioneras como la catalana Dolores Aleu o la valenciana Manuela Solís, licenciadas en 1882 y 1889, respectivamente (Álvarez Ricart); y en el otro extremo del periodo, destaca la libertaria Amparo Poch y Gascón, dedicada a la medicina de la mujer y de la infancia, premio extraordinario de licenciatura en Medicina, en 1928, por la Universidad de Zaragoza (Rodrigo). Numerosas mujeres ocupan el sector farmacéutico y bibliotecario. Igualmente, son muchas las artistas plásticas -pintoras, dibujantes, escultoras, escenógrafas- que ya viven de su arte y participan en exposiciones y certámenes: Laura Albéniz, Lluïsa Vidal, Manuela Ballester, Alma Tapia, Josefina Peñalver, Helia Escudero, Elena Sorolla, Delhy Tejero, etc. (Diego; Arroyo); además de las más conocidas hoy, situadas en la cima de las vanguardias: Maruja Mallo, María Blanchard, Remedios Varo, Nora Borges, Ángeles Santos (Diego y Huici). Muy recuperada en la actualidad está Victorina Durán: escenógrafa, figurinista, pintora, escritora, primera catedrática del Real Conservatorio de Música y Declamación (Moreno). La misma presencia femenina, en la composición e interpretación musical: María Rodrigo, Emiliana de Zubeldi, Elena Romero Barbosa, Luisa Casagemas, M. ${ }^{a}$ Teresa Prieto, Onia Farga, Paquita Madriguera, Emma Chacón, Narcisa Freixas, Lola Vitoria de Giner, etc. (Álvarez Cañíbano). En el campo de la edición hay mujeres profesionales, ya desde el siglo XIX: editoras, impresoras, directoras de colecciones y de revistas (Simón Palmer, «La mujer»). Recuérdese la conocida actividad editora de Concha Méndez y, por otra parte, la citada escuela de tipógrafas creada por Celsia Regis, en 1927, en la que se editan algunos números de La Voz de la Mujer (Rota, «La Voz»)

En el deporte, la figura legendaria fue Lily Álvarez, pionera del tenis femenino español, triunfadora en importantes torneos internacionales (Riaño). Fue la mejor, pero no la única. El ambiente estaba preparado para el deporte femenino (Simón Sanjurjo), aunque siempre entre minorías elitistas, sobre todo en los años treinta. En esta década se celebraron varios campeonatos femeninos: en 1931, el Campeonato de España de atletismo femenino; en 1933, los de natación, esquí, fútbol, cross, hockey. Entre nuestras escritoras, Concha Méndez confiesa su afición al tenis, la gimnasia, las carreras de automóviles, sus triunfos en los campeonatos de natación de Guipúzcoa (Méndez 56); y la periodista y poeta Ana M. a Martínez Sagi

Feminismo/s 37, January 2021, 25-52 
cultivó diversos deportes, siendo campeona nacional de lanzamiento de jabalina en 1931, promotora del Club Femení i d'Esports de Barcelona en 1932 y primera mujer en el Consejo Directivo del Fútbol Club Barcelona, en 1934, cargo del que tuvo que dimitir por su proyecto de crear en el club una sección de fútbol femenino (Prada).

Las nuevas tecnologías de la época crean nuevos puestos de trabajo para la mujer. En Telégrafos, hay mujeres telegrafistas desde 1881, aunque las primeras oposiciones oficiales se convocan en 1909, cuando obtienen plaza Clara Campoamor y Consuelo Álvarez Violeta (Crespo 156-158). Por la tonalidad de su voz, los locutorios de la telefonía son atendidos por señoritas, ya desde 1882, que se mantienen cuando la Compañía Telefónica Nacional de España instala centrales automáticas en 1924. Telefonista fue la poeta Lucía Sánchez Saornil. Y cuando se inaugura la primera emisora oficial de la radiofonía española, Radio Barcelona EAJ-1, el 14 de noviembre de 1924, la primera voz que se escucha es la de una mujer, María Sabater, primera locutora española de radio (Ena, «Modernidad»). Aunque la primera mujer que habló por un micrófono fue la periodista y escritora Teresa de Escoriaza, que pronunció «La primera conferencia feminista»-así se anunció-, el 22 de mayo de 1924, en Radio Ibérica, emisora que sería adquirida por Unión Radio. En su alocución, reproducida por la revista T. S. H. Órgano de «RadioMadrid» y Portavoz de la Federación Nacional de Radioaficionados, tras agradecer el honor de ser la primera mujer en usar «este maravilloso invento de la Radiotelefonía», alaba sus ventajas liberadoras para la mujer:

se trata de iniciar una serie de charlas instructivas exclusivamente para la mujer [...] Porque la Radiotelefonía es el arma con que la mujer, especialmente la española, conquistará la libertad. Con la Radiotelefonía se acabó el aislamiento espiritual en que venía viviendo hasta ahora. (T. S. H.)

Sería el primer espacio, para la mujer, de los muchos programados en la radio de preguerra. La revista Ondas (1925-1935) publica semanalmente la programación diaria, donde se localiza la colaboración de numerosas escritoras: Concha Espina, Matilde Muñoz, Carmen de Burgos, María Lejárraga, Magda Donato, Violeta, Rosa Arciniega, Josefina Carabias, etc. (Simón Palmer, «Imagen»).

Y la revista Estampa (19-II-1929) publica un extenso reportaje sobre la excepcional noticia de «En el tren la primera maquinista española». También 
la aviación admite a la mujer, llegando algunas a profesionalizarse. María Bernaldo de Quirós fue la primera española en obtener, en 1928, el título de piloto y la licencia de la Escuela Nacional Aeronáutica; en 1931, lo obtuvo Mari Pepa Colomer y otras muchas se sumarían a esta nueva actividad (Orellana).

Como dato anecdótico, cuando en 1923, en la Gran Vía madrileña, todavía en obras, se inaugura la primera librería española a nivel europeo, la Casa del Libro, de Espasa-Calpe, presenta la novedad de que eran señoritas quienes atendían al público: cobraban menos que los hombres y eran más adecuadas para atender a las numerosas señoras que acudían a las librerías (Sánchez Vigil 166-174).

La modernización de la sociedad española genera, sobre todo en las grandes urbes, nuevos puestos de trabajo para la mujer. Las ofertas abundan en los anuncios publicados en la prensa, aunque son nuestras escritoras -Nelken, Violeta, Oyarzábal, Magda Donato, Carnés, Carabias, etc.-, en sus colaboraciones periodísticas y, también, en sus obras de ficción, quienes nos muestran esa variedad de trabajos femeninos, además de denunciar las dificultades (precariedad, salarios bajos, ocasionales abusos, inseguridad ...) que la mujer, particularmente de clases sociales bajas, ha de soportar ${ }^{13}$.

\section{CARGOS PÚBLICOS Y POLÍTICOS}

También progresivamente la mujer española va aproximándose a la conquista de su condición de ciudadana, ocupando cargos de representación pública y política (Fagoaga; Capel, El voto; Gómez Blesa, Las intelectuales; Arce). En 1918, son nombradas las dos primeras inspectoras de trabajo por el Instituto de Reformas Sociales, una de ellas fue la escritora y activista del catolicismo social, María de Echarri, que luego ocupó una vocalía en el Consejo Superior de Emigración. En 1924, en virtud del Estatuto Municipal de Primo de Rivera, por el que las mujeres (solteras y viudas) podían ser elegidas para cargos municipales y provinciales, se nombran las cuatro primeras concejales del Ayuntamiento de Madrid, entre ellas la citada Echarri

13. El trabajo femenino es el tema central cultivado por Luisa Carnés, tanto en su periodismo (La Voz, Estampa, Crónica) como en sus cuentos y novelas: Natacha (1930) y Tea Rooms. Mujeres obreras (1934).

Feminismo/s 37, January 2021, 25-52 
(U. C. del A. de M.), así como de otros ayuntamientos españoles. También a iniciativa de Primo de Rivera, y nombradas por él mismo, trece mujeres -de mayoría conservadora- entran, en 1927, en la Asamblea Nacional, entre ellas la misma Echarri y la escritora Blanca de los Ríos ${ }^{14}$. Pero -como es sabido y tanta bibliografía ha generado, por lo que aquí solo dedico un breve recuerdo-será en la República cuando se produzca la incipiente normalización de la actividad política de la mujer, al presentar las candidaturas y ser elegidas, entre las tres legislaturas y por distintos partidos, nueve diputadas: Margarita Nelken, Victoria Kent, Matilde de la Torre, Clara Campoamor, María Lejárraga, Veneranda García Blanco, Francisca Bohigas, Julia Álvarez Resano y Dolores Ibárruri. El 1 de octubre de 1931, las Cortes españolas aprueban el derecho a voto de la mujer, no pudiendo ejercerlo hasta las elecciones de 1933. Y cuando el 25 de febrero de 1932 se aprueba la Ley del Divorcio, tantas veces defendida por nuestras escritoras e intelectuales progresistas desde principios del siglo XX, la modernidad de la sociedad española, con clara contribución femenina, llegaría a cotas que, periodo franquista por medio, tardaría varias décadas en igualar.

\section{LA EDAD DE PLATA DE LA LITERATURA FEMENINA}

Como colofón a esta visión rápida y poliédrica de la evolución de la mujer española en las primeras décadas del siglo XX, no puede faltar una, aunque breve, mención de conjunto a aquellas escritoras que tuvieron gran responsabilidad en la construcción de la nueva mujer por el didactismo ejercido en sus ensayos, su periodismo y en sus obras literarias. Para evitar nomenclaturas generacionales, distingo dos grandes grupos: aquellas nacidas en torno a 1870, que empiezan a publicar en las dos primeras décadas del siglo XX y que -junto a Pardo Bazán, Gimeno de Flaquer y otras escritoras que, habiendo nacido a mediados del XIX, se adentraron en la nueva centuria en plena actividad- fueron las verdaderas pioneras en la nueva literatura femenina del siglo XX: Carmen de Burgos, María Lejárraga, Blanca de los Ríos, Sofía Casanova, Concha Espina, Víctor Català, Carme Karr, Ángela Graupera, Ángeles Vicente, María de Echarri, María Doménech, Pilar Millán

14. Remito a Benítez Palma, «La llegada de la mujer a la Carrera de San Jerónimo...», en este número de Feminismo/s.

Feminismo/s 37, January 2021, 25-52 
Astray, Matilde Ras, Isabel Oyarzábal, etc.; y las nacidas a partir de 1885, que publican sus principales obras en las décadas de 1920 y 1930, enriqueciendo el terreno ya abonado por las anteriores: Margarita Nelken, Magda Donato, Adela Carbone, Gloria de la Prada (publica desde 1910), M. ${ }^{a}$ Luz Morales, Elena Fortún, Matilde Muñoz, Teresa de Escoriaza, Rosa Chacel, Lucía Sánchez Saornil, Halma Angélico, Concha Méndez, M. ${ }^{a}$ Teresa León, Ernestina de Champourcín, Josefina de la Torre, Pilar Valderrama, Sara Insúa, Luisa Carnés, Carlota O’Neill, Elisabeth Mulder, Rosa Arciniega (peruana, pero publicó en la España de 1930), Federica Montseny, Ana M. ${ }^{a}$ Martínez Sagi, Carmen Conde, Hildegart Rodríguez, etc. Unas y otras, aun mostrando distintas ideologías, tendencias literarias y valores artísticos, aportan unos rasgos innovadores que -sin poder comentarlos aquí- contribuirán a modificar el canon literario imperante durante siglos, mantenido por una tradición fundamentalmente masculina, y a diseñar la nueva mujer del siglo XX (Ena, «Jaque»). Constituyen, sin duda, «la Edad de Plata de la literatura femenina».

\section{REFERENCIAS BIBLIOGRÁFICAS}

Aguilera Sastre, Juan, e Isabel Lizárraga. De Madrid a Ginebra. El feminismo español y el VIII Congreso de la Alianza Internacional para el Sufragio de la Mujer (1920). Barcelona: Icaria, 2010.

Aguilera Sastre, Juan. «Las fundadoras del Lyceum Club español». Brocar 35 (2011): 65-90.

Alcalá Cortijo, Paloma, Capi Corrales y Julia López, coords. Ni tontas ni locas. Las intelectuales en el Madrid del primer tercio del siglo XX. Madrid: FECYT, 2009.

Álvarez Ricart, Carmen. La mujer como profesional de la medicina en la España del siglo XIX. Barcelona: Anthropos, 1998.

Álvarez Cañíbano, Antonio, coord. Compositoras españolas: la creación musical femenina desde la Edad Media hasta la actualidad, Madrid: Centro de Documentación de Música y Danza, 2008.

Arroyo Arce, Nadia, coord. Amazonas del arte nuevo. Catálogo. Madrid: Fundación Mapfre, 2008.

Arce Pinedo, Rebeca. Dios, Patria y Hogar. La construcción social de la mujer española por el catolicismo y las derechas en el primer tercio del siglo XX. Santander: Ediciones de la Universidad de Cantabria, 2008. 
Bados, Concepción. «Isabel Oyarzábal, editora y redactora: La Dama y La Vida Ilustrada». En prensa: escritoras y periodistas en España (1900-1936). Eds. Margherita Bernard e Ivana Rota. Bergamo: University Press, Sestante Edizioni, 2010. 15-44.

Ballarín, Pilar. La educación de las mujeres en la España contemporánea (siglos XIX-XX). Madrid: Síntesis, 2001.

Bernard, Margherita. «Los 'reportajes vividos' de Magda Donato». Papel de mujer y mujeres de papel. Periodismo y comunicación del siglo XIX a nuestros días. Eds. Margherita Bernard, Luisa Chierichetti, Mercedes González e Ivana Rota. Bergamo: University Press, 2008. 105-133.

Bernard, Margherita. «Moda y modernidad en las crónicas de Magda Donato». Nuevos modelos. Cultura, moda y literatura (España 1900-1939). Eds. Margherita Bernard e Ivana Rota. Bergamo: University Press, 2012. 33-56. Bernard, Margherita e Ivana Rota, eds. En prensa. Escritoras y periodistas en España (1900-1939). Bergamo: University Press, 2010.

Bernárdez, Asunción, dir. Escritoras y periodistas en Madrid (1876-1926). Madrid: Ayuntamiento, 2007.

Bianchi, Marina. «Los artículos 'a lo femenino' de María de la Concepción Gimeno de Flaquer». Papel de mujer y mujeres de papel. Periodismo y comunicación del siglo XIX a nuestros días. Eds. Margherita Bernard, Luisa Chierichetti, Mercedes González e Ivana Rota. Bergamo: University Press, 2008. 21-49. Capdevila, Nuria. Mujeres inciertas. Voces olvidadas de nuestro feminismo. Madrid: Horas y Horas, 2009.

Capel, Rosa. El trabajo y la educación de la mujer en España (1900-1939). Madrid: Ministerio de Cultura, 1986.

Capel, Rosa dir. El voto de las mujeres: 1877-1978. Madrid: Editorial Complutense, 2003.

Crespo, Victoria. Consuelo Álvarez Violeta. Telegrafista, periodista y defensora de los derechos de la mujer. Monografía. Cuadernos de Historia de las Telecomunicaciones 9, 2016.

Cueva, Almudena de la, y Margarita Márquez Padorno, eds. Mujeres en vanguardia: la Residencia de Señoritas en su centenario (1915-1936). Catálogo. Madrid: Residencia de Estudiantes, 2015.

Darío, Rubén. «La mujer española». La España Contemporánea. Obras Completas. Vol. XIX. Madrid: Mundo Latino, 1918, 321-328.

Diego, Estrella de. La mujer y la pintura del XIX español. Madrid: Cátedra, 1987. 
Diego, Estrella de, y Fernando Huici, Fuera de orden. Mujeres de la vanguardia española. Catálogo. Madrid: Fundación Cultural Mapfre Vida, 1999.

Ena Bordonada, Ángela. Novelas breves de escritoras españolas (1900-1936). Madrid: Castalia, 1989.

Ena Bordonada, Ángela. «Jaque al 'ángel del hogar': escritoras en busca de la nueva mujer del siglo XX». Romper el espejo: La Mujer y la Transgresión de Códigos en la Literatura Española. Ed. M. José Porro. Córdoba: U de Córdoba, 2001. 89-111.

Ena Bordonada, Ángela. «Modernidad y literatura femenina: Mujer y radiofonía». Con voz propia. La mujer en la literatura española de los siglos XIX y XX. Eds. Pilar Celma y Carmen Morán. Segovia: Instituto de la Lengua Castellano y Leonés, 2006. 137-150.

Ena Bordonada, Ángela. «La memoria del viaje: viajes y libros de viajes de escritoras españolas del primer tercio del siglo XX». Mujer y memoria. Representación, Identidad y Códigos. Eds. M. . José Porro y Blas Sánchez. Córdoba: U de Córdoba, 2009. 103-134.

Ena Bordonada, Ángela. «El retrato de mujer en la narrativa femenina de la Edad de Plata». Imágenes femeninas en la literatura española y las artes escénicas (siglos XX y XXI). Coords. M. ${ }^{a}$ Francisca Vilches y Pilar Nieva. Cincinatti, Ohio: Society of Spanish-American Studies, 2012. 35-49.

Ena Bordonada, Ángela. «Un relato lésbico de 1907: Carnestoltes de Caterina Albert-Víctor Catalá». Cartografía literaria en homenaje al profesor Romera Castillo. Vol. 1. Eds. Guillermo Laín y Rocío Santiago. Madrid: Visor, 2018. 707-722.

Ezama Gil, Ángeles. «La Unión ibérica de escritoras entre los siglos XIX y XX». Estudios Portugueses: Revista de Filología Portuguesa 10 (2010): 57-78.

Ezama Gil, Ángeles. «Las colaboraciones de Josefina Carabias en La Voz (19321935). El Argonauta Español 9 (2012). 15 enero 2020. http://argonauta.revues. org/1561

Ezama Gil, Ángeles. La educación de la mujer a comienzos del siglo XX. El centro Iberoamericano de cultura popular femenina (1906-1926). Málaga: Atenea, 2015.

Ezama Gil, Ángeles. Las nuevas musas suben a la tribuna. Visibilidad y autoridad de las mujeres en el Ateneo de Madrid (1882-1939). Logroño: Geneuve, 2018. Fagoaga, Concha. La voz y el voto de las mujeres. El sufragismo en España. 18771931. Barcelona: Icaria,1985. 
Fernández, Pura, coord. No hay nación para este sexo: la Re(d)pública transatlántica de las Letras: escritoras españolas y latinoamericanas (1824-1936). Madrid y Frankfurt: Iberoamericana, Vervuert, 2015.

Flecha, Consuelo. Las primeras universitarias en España: 1872-1910. Madrid: Narcea, 1996.

Ghiraldo, Alberto. El archivo de Rubén Darío. Buenos Aires: Losada, 1943.

Gies, David T. «Mujer como Dios manda: Antifeminismo y risa en Una mujer literata (1851) de Gutiérrez del Alba». Scriptura 15 (1999):169-179.

Gómez Blesa, Mercedes. Las intelectuales republicanas. La conquista de la ciudadanía. Madrid: Biblioteca Nueva, 2007.

Gómez Blesa, Mercedes. Modernas y vanguardistas. Las mujeres-faro de la Edad de Plata. Madrid: Huso, 2019.

González Sanz, Alba. Contra la destrucción teórica. Teorías feministas en la España de la Modernidad. Oviedo: KRK, 2018.

Huertos, Luis G. «Vida rota». Literatura moderna. Barcelona: Librería de Feliu y Susanna, 1911. 145-160.

Hurtado, Amparo. «Biografía de una generación: las escritoras del 98». Breve historia feminista de la literatura española. Vol 5. Dirs. Maryellen Bieder e Iris Zavala. Barcelona: Anthropos, 1998. 139-154.

Labajo González, María Trinidad. Lecturas. Una revista popular de literatura. Trayectoria y contenidos (1921-1936). Madrid: Diss. U Complutense, 2001.

López-Ríos, Santiago. «Introducción». Carmen Castilla, Diario de viaje a Estados

Unidos. Un año en Smith College (1921-1922). Valencia: U de València / Biblioteca Javier Coy d'Estudis Nord-Americans, 2012. 21-69.

Magallón Portolés, Carmen. Pioneras españolas en las ciencias. 1908-1936. Madrid: CSIC, 2004.

Mangini, Shirley. Las modernas de Madrid: las grandes intelectuales españolas de la vanguardia. Barcelona: Península, 2001.

Martínez Sierra, María. Gregorio y yo: medio siglo de colaboración. Valencia: Pretextos, 2000.

Méndez, Concha. Memorias habladas, memorias armadas. Ed. Paloma Ulacia Altolaguirre. Sevilla: Renacimiento, 2018.

Moreno, Eva. «Introducción». Victorina Durán, A teatro descubierto. Madrid: Torremozas, 2019, 9-56.

Nieva de la Paz, Pilar. Escritoras españolas contemporáneas. Identidad y vanguardia. Berlín: Peter Lang, 2018. 
Núñez Rey, Concepción. Carmen de Burgos, Colombine, periodista universal. Sevilla: Fundación José Manuel Lara, Ayuntamiento de Níjar, 2019.

Orellana, Almudena. «Maria Bernaldo de Quirós: primera aviadora española». Asparkia: Investigació feminista 27 (2016): 147-161.

Palomo, Pilar y Concepción Núñez, eds. Sofía Casanova y las periodistas de entresiglos. Madrid: Espéculo. Col. eLibros, 1, 2016.

Pasadolos, Mercedes. El traje como reflejo de lo femenino: evolución y significado. Madrid, 1898-1915. Madrid: UCM, 2003.

Pintos, Margarita. Concepción Gimeno de Flaquer. Del sí de las niñas al yo de las mujeres. Madrid: Plaza y Valdés, 2016.

Piñón Varela, Pilar. Go West Young Woman! Redes transatlánticas e internacionalismo cultural. Las mujeres como protagonistas del intercambio académico entre España y los Estados Unidos (1919-1939). Diss. UNED, 2016.

Plaza Angulo, Inmaculada. «Estereotipos sobre las escritoras en los prólogos a las poetas españolas de preguerra». Imágenes femeninas en la literatura española y las artes escénicas (siglos XX y XXI). Coords. M. . Francisca Vilches y Pilar Nieva. Cincinatti, Ohio: Society of Spanish-American Studies, 2012. 85-101.

Prada, Juan Manuel de. «Introducción». Ana María Martínez Sagi, La voz sola. Madrid: Fundación Banco de Santander, 2019. 8-29.

Quiles Faz, Amparo. Isabel Oyarzábal. Mujer, voto y libertad. Sevilla: Renacimiento, 2013.

Ramírez, Carmen. Mujeres escritoras en la prensa andaluza. Sevilla: Universidad de Sevilla. 2000.

Ramírez Ángel, Emiliano: «Donde nace el amor». Literatura moderna. Barcelona: Librería de Feliu y Susanna, 1911. 2-17.

Rebok, Sandra, ed. Traspasar fronteras: un siglo de intercambio científico entre España y Alemania. Madrid, CSIC, 2010. 29 octubre 2020. http.//eprints. ucm.es/11036

Riaño González, Catalina. Historia cultural del deporte y la mujer en la España de la primera mitad del siglo XX a través de la vida y obra de Elia María González Álvarez y Lopez Chicheri, «Lilí Álvarez». Madrid: Consejo Superior de Deportes, 2004.

Rodrigo, Antonina. Amparo Poch y Gascón. Textos de una médica libertaria. Zaragoza: Diputación, 2002. 
Rota, Ivana. «La Voz de la Mujer (1917-1931) y la formación de la mujer tipógrafa y periodista». Escritoras españolas en los medios de prensa (168-1936). Eds. Carmen Servén e Ivana Rota. Sevilla: Renacimiento, 2013. 207-237.

Saco, Eduardo. «La literata». Las españolas pintadas por los españoles. Dir. Roberto Robert. Vol. I. Madrid: Imprenta de J. R. Morete, 1871. 67-73.

Sáez, Begoña (2008). «Críticos, críticas y criticadas: El discurso crítico ante la mujer de letras». La mujer de letras o la letraherida. Discursos y representaciones sobre la mujer escritora en el siglo XIX. Eds. Pura Fernández y MarieLinda Ortega. Madrid: CSIC, 2008. 33-52.

Sánchez García, Raquel. Señoras fuera de casa. Mujeres del XIX: la conquista del espacio público. Madrid: Catarata, 2019.

Sánchez Vigil, Juan Miguel. Calpe. Paradigma editorial (1918-1925). Madrid: Trea, 2005.

Scanlon, Geraldine M. La polémica feminista en la España contemporánea, 18681974. Madrid: Akal, 1986.

Servén, Carmen. «La labor de María Luz Morales en El Hogar y la Moda (19211936)». En prensa. Escritoras y periodistas en España (1900-1936). Eds. Margherita Bernard e Ivana Rota. Bergamo: University Press, 2010. 87-108. Servén, Carmen. «Literatura, periodismo y cine: María Luz Morales en La Vanguardia». Escritoras españolas en los medios de prensa (1868-1936). Eds. Carmen Servén e Ivana Rota. Sevilla: Renacimiento, 2013. 267-289.

Servén, Carmen e Ivana Rota, eds. Escritoras españolas en los medios de prensa (1868-1936). Sevilla: Renacimiento, 2013.

Simón Palmer, M. ${ }^{a}$ Carmen. «La mujer en el mundo editorial español». Escribir en España entre 1840 y 1876. Coord. Marie-Linda Ortega. Madrid: Visor, 2002. 35-56.

Simón Palmer, M. ${ }^{a}$ Carmen. "Imagen sonora: escritoras en los inicios de la radio». Imágenes femeninas en la literatura española y las artes escénicas (siglos XX y XXI). Coords. María Francisca Vilches y Pilar Nieva. Cincinatti, Ohio: Society of Spanish-American Studies, 2012. 135-150.

Simón Palmer, M. ${ }^{a}$ Carmen. «Escritoras en la prensa catalanista». Escritoras españolas en los medios de prensa 1868-1936. Eds. Carmen Servén e Ivana Rota. Sevilla: Renacimiento, 2013. 290-317.

Simón Sanjurjo, Juan Antonio. «El papel de la mujer en el origen y desarrollo del deporte en España (1900-1939)». Actas del Primer Congreso Internacional «Las Mujeres en la Esfera Pública, Filosofía e Historia Contemporánea». Coords. 
Laura M. Branciforte, Carmen González, Montserrat Huguet, Rocío Orsi. Madrid: CERSA, 2009. 77-102.

Simonis, Angie. Yo no soy esa que tú imaginas. El lesbianismo en la narrativa española del siglo XX a través de sus estereotipos. Alicante: U de Alicante, Centro de Estudios de la Mujer, 2009.

Sobejano, Gonzalo. Novela española de nuestro tiempo. Madrid: Marenostrum, 3. ${ }^{a}$ ed. 2005.

T. S. H. Órgano de «Radio-Madrid» y Portavoz de la Federación Nacional de Radioaficionados. 25 mayo 1924.

U. C. del A. de M. «Las primeras concejales del Ayuntamiento de Madrid». Madrid: Revista de la Biblioteca, Archivo y Museo, 1925.

Usó, Juan Carlos. Gloria Laguna. Ingenio castizo, mito literario y lesbianismo chic. Santander: El Desvelo, 2017.

Yanes Pérez, José Santiago. Estudio histórico-jurídico del acceso de la mujer a la abogacía en España. Diss. U de Las Palmas, 2015.

Zulueta, Carmen de. Misioneras, feministas, educadoras. Historia del Instituto Internacional. Madrid: Castalia, 1984.

Zulueta, Carmen de y Alicia Moreno. Ni convento ni college: la Residencia de Señoritas. Madrid: Residencia de Estudiantes, 1993. 